\title{
EFFECT OF SOIL PROFILE CHARACTERISTICS ON THE SEISMIC SLIDING DISPLACEMENT OF SLOPES
}

\author{
Loukas C. Katsenis ${ }^{1}$, Constantine A. Stamatopoulos ${ }^{2}$, Vassilis P. Panoskaltsis ${ }^{1}$ \\ ${ }^{1}$ Department of Civil Engineering, Demokritos University of Thrace, \\ University Campus Xanthi-Kimmeria, 67100 Xanthi, Greece \\ e-mails: katsenisloukas@yahoo.gr, vpanoska@civil.duth.gr \\ ${ }^{2}$ Stamatopoulos and Associates Co.; Hellenic Open University; 5 Isavron str, 11471 Athens, Greece \\ e-mail:k.stam@saa-geotech.gr
}

\begin{abstract}
In earthquake analyses, usually the seismic displacement is estimated by the sliding-block model, where a rigid block rests on an inclined plane and every time that the applied horizontal acceleration is larger than the critical horizontal acceleration value for relative motion, the block slides. This model is used for the prediction of permanent seismic movement of slopes along a predefined slip surface, by appropriately selecting the equivalent critical and applied acceleration values of the rigid block. However, the input seismic motion is usually specified at the underlying bedrock and the seismic displacement along a slip surface depends not only on the resistance along the slip surface, but also on the dynamic characteristics of the soil both above and below the slip surface. Based on the above, the present work investigates and proposes expressions relating the ratio of the seismic displacement of slopes along a slip surface and the corresponding displacement of the sliding-block model for similar applied acceleration and critical acceleration of the slip surface in terms of characteristics of the soil profile both above and below the slip surface. The proposed expressions were obtained based state-of-theart description of the dynamic response and results of previous dynamic seismic sliding displacement analyses. Parametric analyses using a recently developed numerical code were performed to calibrate and validate the proposed expressions. In these analyses, different acceleration histories measured at rock sites are applied below soil layers with a slip surface with varying critical acceleration value and dynamic properties both above and below the slip surface.
\end{abstract}

Keywords: slopes, sliding-block model, dynamic response, seismic displacement, slip surface, coupled analyses 


\section{INTRODUCTION}

The seismic displacement of slopes usually occurs along a slip surface [1]. Engineers usually assess the seismic safety of slopes using the dynamic factor of safety calculated from loads. However, evaluations based on the dynamic factor of safety have the serious drawback that they do not consider the seismic displacement, which is directly related to damage. In earthquake analyses, usually the seismic displacement is estimated by the sliding-block model [2], where a rigid block rests on an inclined plane and every time that the applied horizontal acceleration is larger than the critical horizontal acceleration value for relative motion (ac), the block slides. This model is used for the prediction of permanent seismic movement of slopes and retaining structures along a predefined slip surface, by appropriately selecting the equivalent critical and applied acceleration values of the rigid block $[1,3]$.

Different empirical expressions have been proposed predicting the seismic displacement of the sliding-block model, in terms, primarily, of the ratio of the maximum acceleration of the applied seismic motion by the critical horizontal acceleration for sliding [3]. In addition, some of these expressions use other than the maximum acceleration parameters of the seismic motion, such as the maximum velocity or the Arias Intensity, or parameters of the earthquake that produced the seismic motion, such as its earthquake magnitude or its earthquake fault distance [4,5]. Furthermore, region-specific empirical expressions have been proposed predicting the seismic displacement of the sliding-block model, as different regions have different earthquake faults and geological profiles conditions, and thus potentially different applied seismic motions characteristics [6].

However, the input seismic motion is usually specified at the underlying bedrock and the seismic displacement along a slip surface depends on both the dynamic characteristics of the sliding mass, and the soil profile below [8]. Based on the above, it is of interest for practicing engineers, to relate the seismic displacement along slip surfaces, not only on characteristics of the applied seismic motion and the critical horizontal acceleration for sliding of the slip surface, but also to the dynamic soil properties both above and below the slip surface. Expressions have been proposed predicting the seismic displacement of slopes in terms of not only characteristics of the applied seismic motion and the critical horizontal acceleration for sliding, but also on the dynamic characteristics of the sliding mass [7]. Furthermore, Katsenis et al [9] proposed empirical expressions relating the ratio of the seismic displacement of slopes along a slip surface and the corresponding displacement of the sliding-block model for similar applied acceleration and critical acceleration of the slip surface considering the dynamic soil profile characteristics both above and below the slip surface. Their relationships are in terms of the soil profile type of the slope according to Eurocode 8 [10] and the depth of the slip surface. Yet, the dynamic response of soil layers is related to its dominant period [7, 8], and Eurocode profile types provide only an approximate prediction of the actual dynamic response.

The present work extends the Katsenis et al. [9] work by proposing an empirical expression predicting the seismic displacement of slopes where the soil profile has any shear velocity value and depth both above and below the slip surface. In order to achieve this goal, below, first a critical literature review of the dynamic effect on the seismic displacement of slopes is pre- 
sented. Then, based on this critical review, equations simulating the dynamic effect on the seismic displacement of slopes are proposed. Following, a data base of seismic motions measured at rock sites is obtained, mainly recorded in the European-Mediterranean regions and using this data base an evaluation of the model parameters of the proposed equations and an assessment of the accuracy of the model is performed. Finally, the paper discusses further validation and application of the proposed equation.

\section{CRITICAL LITERATURE REVIEW OF THE DYNAMIC EFFECT ON THE SEISMIC DISPLACEMENT OF SLOPES}

\subsection{Eurocode}

According to Eurocode 8 (European Standard, 2003), as illustrated in Fig. 1, the dynamic response of elastic systems (S) depends on the critical period of the system (Ts) according to the following equations:

$$
\begin{array}{ll}
\mathrm{Ts}<\mathrm{Ta} & \mathrm{S}(\mathrm{Ts})=1+\mathrm{A} \mathrm{Ts} / \mathrm{Ta} \\
\mathrm{Ta} \geq T s \geq T b & \mathrm{~S}(\mathrm{Ts})=1+\mathrm{A} \\
\mathrm{Ts}>\mathrm{Tb} & \mathrm{S}(\mathrm{Ts})=(1+\mathrm{A})(\mathrm{Tb} / \mathrm{Ts})^{\mathrm{B}}
\end{array}
$$

Where the parameters A and B typically equal 0.25 and 2/3 respectively and the parameters $\mathrm{Ta}$ and $\mathrm{Tb}$ depend on the underlying soil type and for rock sites they equal $\mathrm{Ta}=0.10 \mathrm{~s} \mathrm{~Tb}=0.40 \mathrm{~s}$.

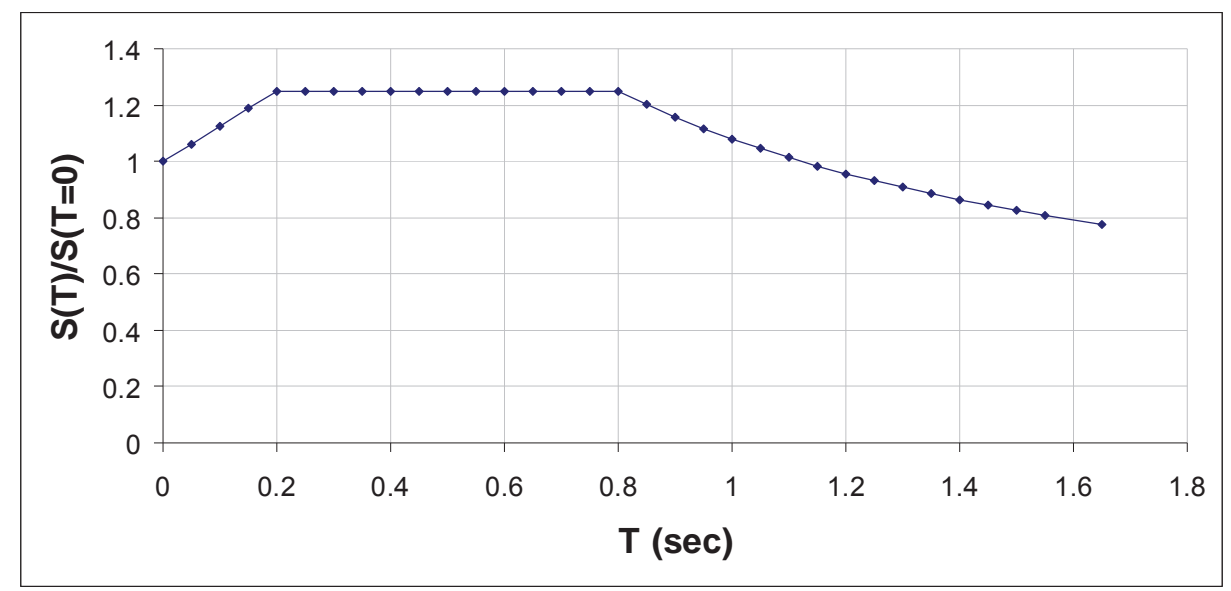

Figure 1: Seismic response in terms of Ts as predicted by Eurocode 8 (European Standard, 2003) for rock sites.

\subsection{Work by Rathje and Bray [7] and Bray and Travasarou [13]}

The effect of the dynamic response of the sliding mass on the seismic displacement along slip surfaces has been modelled among others by Rathje and Bray [7]. They consider the 1dimensional geometry of Fig. 2a where a horizontal shear wave propagates vertically above a 
slip surface with critical acceleration ac at a body with height $\mathrm{h}$ and shear wave velocity Vs and identify the critical period of the system, as

$$
\mathrm{Ts}=4 \mathrm{~h} / \mathrm{Vs}
$$

Fig. $2 \mathrm{~b}$ presents typical predictions of their model: The variation of sliding displacement with Ts/Tm, where Tm is the mean period of the applied seismic motion, for the Aegion 1995 seismic motion with $\mathrm{ac}=0.5 \mathrm{~m} / \mathrm{s}^{2}, \mathrm{~h}=15 \mathrm{~m}, \rho==2 \mathrm{Mg} / \mathrm{m} 3$ and damping $\lambda=0.15$ is presented. In Fig. $2 b$ it can be observed that, similarly to Fig. 1, the effect of dynamic response (a) does not exist for $\mathrm{Ts}=0$, (b) as Ts increases, the dynamic effect increases and it produces maximum response approximately when $\mathrm{Ts}=\mathrm{Tm}$ and (c) as Ts further increases beyond $\mathrm{Tm}$, it decreases the final seismic displacement along the slip surface $\left(\mathrm{u}_{\mathrm{f}}\right)$ towards zero.

Consistently, Bray and Travasarou [13] proposed empirical expressions relating the seismic displacement, in addition to the critical acceleration ac and characteristics of the applied seismic motion such as the earthquake magnitude $\mathrm{u}_{\mathrm{f}}$, to Ts.

(a)

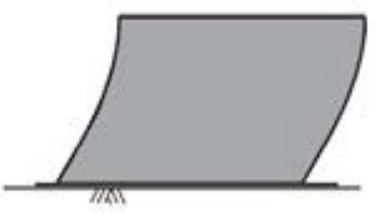

(b)

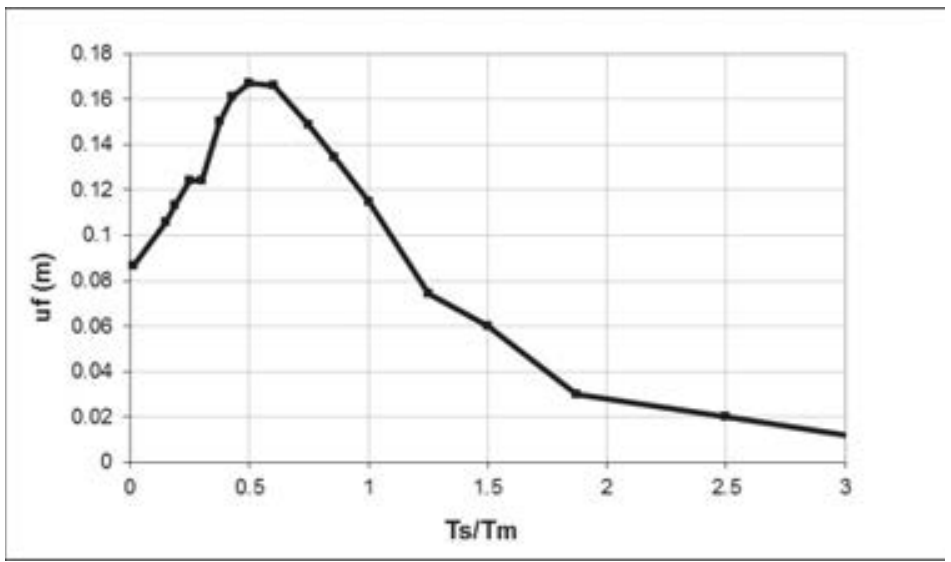

Figure 2: (a) The Rathje and Bray [7] model and (b) typical predictions of the model: Variation of sliding displacement with Ts $/ \mathrm{Tm}$ for rigid and dynamic analyses. The Aegion 1995 seismic motion with ac $=0.5 \mathrm{~m} / \mathrm{s} 2, \mathrm{~h}=$ $15 \mathrm{~m}, \rho=2 \mathrm{Mg} / \mathrm{m}^{3}$ and $\lambda=0.15$ is presented.

\subsection{The Katsenis et al. [9, 11] model}

In the analyses described above the effect of the soil profile below the slip surface on the seismic displacement has not been studied. The Katsenis et al $[9,11]$ model, is a cost-effective 
model which can study it: As shown in Fig. 3b, it considers the 1-dimensional dynamic response of a horizontal soil profile of depth $\left(h_{1}+h_{2}\right)$ with a slip element at depth $h_{1}$. Different shear wave velocities $\left(\mathrm{V}_{\mathrm{s}-1}, \mathrm{~V}_{\mathrm{s}-2}\right)$, densities $\left(\rho_{1}, \rho_{2}\right)$ and damping $\left(\lambda_{1}, \lambda_{2}\right)$ may exist above and below the slip element. The slip element simulates the seismic displacement of the conventional sliding-block model, where its resistance is defined by the critical horizontal value $\left(\mathrm{a}_{\mathrm{c}}\right)$, for which relative movement in only one direction occurs. The two bodies move a horizontal distance $\mathrm{x}_{\mathrm{i}}$, velocity $\mathrm{x}_{\mathrm{i}}^{\prime}$ and acceleration $\mathrm{x}_{\mathrm{i}} \mathrm{i}$, where $\mathrm{i}$ takes the values 1 and 2 for bodies 1 and 2 respectively. The corresponding field configuration is that of a slope with a slip surface where seismic displacement may accumulate as a result of a horizontal shear wave, illustrated in Fig. 3a

(a)

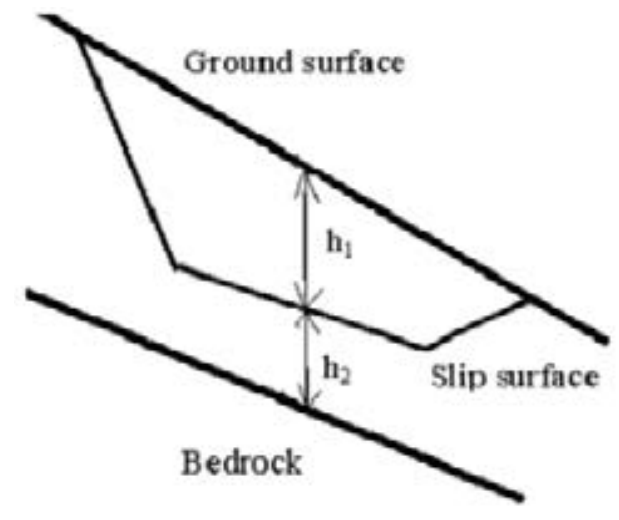

(b)

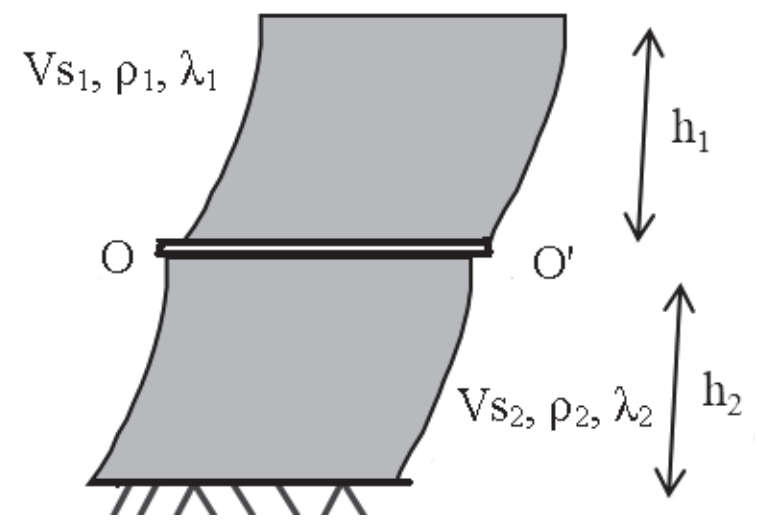

Figure 3: The Katsenis et al, (2020) model: (a) field configuration of a slope with a slip surface where seismic displacement may accumulate as a result of a horizontal shear wave, (b) simulation of (a) with a 1-D dynamic system of 2 continuous bodies separated by a horizontal slip element. In the dynamic system (b) slippage may occur along AA'.

\subsection{Results of the Katsenis et al. [11] model}

Katsenis et al. [11] define

$\mathrm{Ts} 1=4 \mathrm{~h}_{1} / \mathrm{V}_{\mathrm{s}-1}$

Ts-ave $=4\left(\mathrm{~h}_{1} / \mathrm{V}_{\mathrm{s}-1}+\mathrm{h}_{2} / \mathrm{V}_{\mathrm{s}-2}\right)$

and Fig. 4 presents a typical computed permanent seismic displacement $\left(\mathrm{u}_{\mathrm{f}}\right)$ response of their model. In particular, the computed displacement $\left(\mathrm{u}_{\mathrm{f}}\right)$ for the Aegion 1995 seismic motion with $\mathrm{ac}=0.5 \mathrm{~m} / \mathrm{s} 2, \mathrm{~h}_{1}+\mathrm{h}_{2}=30 \mathrm{~m}, \rho_{1}=\rho_{2}=2 \mathrm{Mg} / \mathrm{m} 3$ and $\lambda_{1}=\lambda_{2}=0.15$ (a) versus $\mathrm{Ts} 1 / \mathrm{Tm}$ for $\mathrm{V}_{\mathrm{s}-2}=\mathrm{V}_{\mathrm{s}-1}$, $\mathrm{h}_{2}=1 \mathrm{~m}, 15 \mathrm{~m}, 25 \mathrm{~m}$, (b) versus Ts $1 / \mathrm{Tm}$ for $\mathrm{h}_{2}=15 \mathrm{~m}$ and (c) versus Ts-ave/Tm for the cases (a) and (b) is presented.

It can be observed that the effect of the soil profile both above and below the slip surface on the seismic displacement is considerable and that if $u_{f}$ is plotted in terms of the ratio Ts-ave/Tm, the scatter in results for different $\mathrm{V}_{\mathrm{s}-2}$ and $\mathrm{h}_{2}$ values decreases considerably. It is inferred that the dynamic effect on $u_{f}$ can partly be interpreted by relating $u_{f}$ to Ts-ave. In particular, similarly 
to the response of Figs. 1 and 2, but replacing Ts with Ts-ave, it can be observed that the dynamic response (a) does not exist for Ts-ave $=0$, (b) as Ts-ave increases, the dynamic effect increases and it produces maximum response approximately when Ts-ave $=\mathrm{Tm}$ and (c) as Tsave further increases beyond $\mathrm{Tm}$, it decreases the final seismic displacement along the slip surface $\left(\mathrm{u}_{\mathrm{f}}\right)$ towards zero.

Furthermore, Katsenis et al. [11] illustrate that the dynamic response play an important role for small seismic displacement, but a smaller role for large seismic displacement $(>0.5 \mathrm{~m})$. Typical results are given in Fig. 5, where the ratio of the rigid and dynamic $u_{f}$ value tends to zero as ac decreases. Indeed, as identified by previous researchers also [14], large seismic displacement corresponds to low critical acceleration value, which limits the seismic actions transmitted across the slip surface, and thus the dynamic effect.

(a)

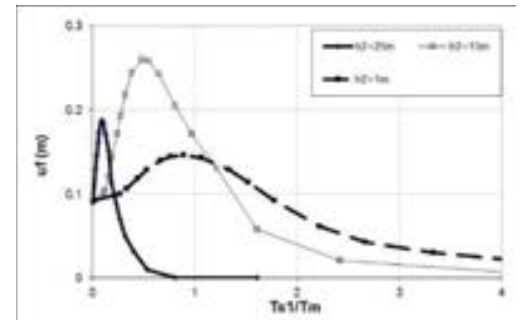

(b)

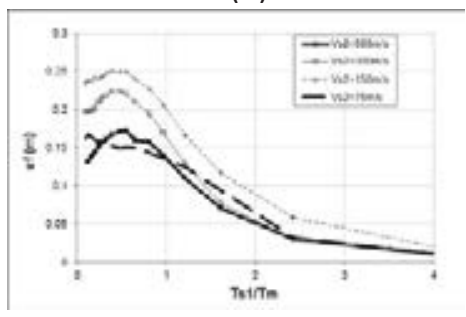

(c)

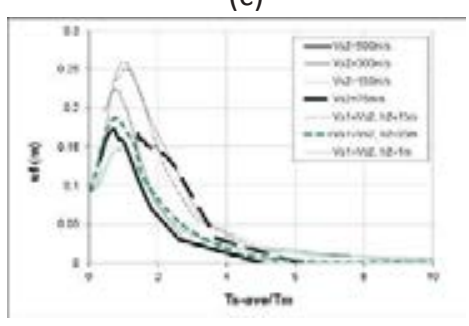

Figure 4: The computed permanent seismic displacement $\left(\mathrm{u}_{\mathrm{f}}\right)$ for the Aegion 1995 seismic motion with $\mathrm{a}_{\mathrm{c}}=0.5 \mathrm{~m} / \mathrm{s} 2, \mathrm{~h}_{1}+\mathrm{h}_{2}=30 \mathrm{~m}, \rho_{1}=\rho_{2}=2 \mathrm{Mg} / \mathrm{m} 3$ and $\lambda_{1}=\lambda_{2}=0.15$ (a) versus Ts $1 / \mathrm{Tm}$ for $\mathrm{V}_{\mathrm{s}-2}=\mathrm{V}_{\mathrm{s}-1}, \mathrm{~h}_{2}=1 \mathrm{~m}, 15 \mathrm{~m}, 25 \mathrm{~m}$, (b) versus $\mathrm{Ts} 1 / \mathrm{Tm}$ for $\mathrm{h}_{2}=15 \mathrm{~m}$ and $\mathrm{V}_{\mathrm{s}-2}=75,150,300,500 \mathrm{~m} / \mathrm{s}$ and (c) versus Ts-ave/Tm for the cases (a) and (b)

[11].

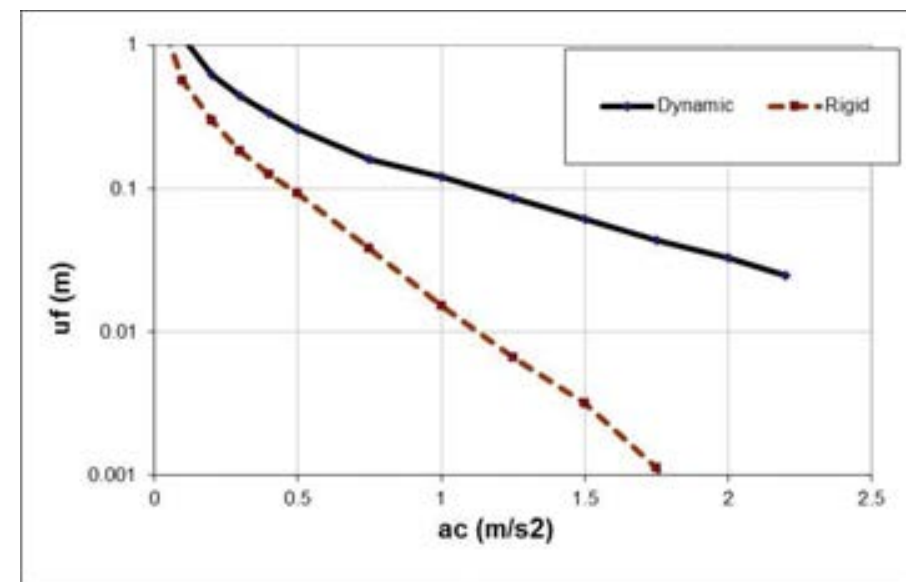

Figure 5: Computed permanent seismic displacement $\left(\mathrm{u}_{\mathrm{f}}\right)$ by [11] for the elastic and rigid analyses in terms of of $\mathrm{a}_{\mathrm{c}}$ for the Aegion 1995 seismic motion, $\mathrm{h}_{1}=\mathrm{h}_{2}=15 \mathrm{~m}, \mathrm{~V}_{\mathrm{s}-1}=\mathrm{V}_{\mathrm{s}-2}=200 \mathrm{~m} / \mathrm{s}, \rho 1=\rho 2=2 \mathrm{Mg} / \mathrm{m} 3$, $\lambda_{1}=\lambda_{2}=0.15$.

\subsection{Previous empirical equation}

Different empirical expressions have been proposed predicting the seismic displacement of the conventional sliding-block model $\left(\mathrm{u}_{\mathrm{f}-\mathrm{bl}}\right)$ in terms of $\mathrm{a}_{\mathrm{c}}$ and characteristics of the seismic motion such as $\mathrm{a}_{\max }$, Arias intensity, earthquake magnitude etc. [2-6]. In addition, some of these 
expressions are region-specific [7]. Katsenis et al. [9] in order, to separate the dynamic effect from the seismic displacement accumulating along the slip surface for rigid blocks, propose to relate $\mathrm{u}_{\mathrm{f}}$ on the conventional sliding-block model $\left(\mathrm{u}_{\mathrm{f}-\mathrm{bl}}\right)$ seismic displacement for the same applied seismic motion and critical acceleration value, as

$\mathrm{u}_{\mathrm{f}}=\mathrm{R} \mathrm{u}_{\mathrm{f}-\mathrm{bl}}$

where the factor $\mathrm{R}$ simulates the dynamic effect and depends on various factors such as $\mathrm{u}_{\mathrm{f}-\mathrm{bl}}$, the soil profile type and the depth of the slip surface.

\section{PROPOSED EQUATION PREDICTING THE DYNAMIC EFFECT ON THE SEISMIC DISPLACEMENT OF SLOPES}

The problem considered is that of Fig. 3a where a seismic horizontal motion is applied at the bedrock underlying a soil profile where a potential slip surface exists at some depth, which is simulated with the system of Fig. $3 b$.

In order, to separate the dynamic effect from the seismic displacement accumulating along the slip surface for the same seismic motion, which has been predicted by previously proposed empirical equations, similarly to [9], we relate $u_{f}$ on the conventional sliding-block model seismic displacement for the same applied seismic motion and critical acceleration value $\left(\mathrm{u}_{\mathrm{f}} \mathrm{bl}\right)$. More specifically, we propose the following equation to predict $u_{\mathrm{f}}$ :

$$
\mathrm{u}_{\mathrm{f}}=\mathrm{u}_{\mathrm{f}-\mathrm{bl}} \mathrm{Kdyn}
$$

At this point it should be noted that $u_{f-b l}$ equals to $u_{f}$ in the case of a very stiff or of a very shallow soil profile, where Ts-ave tends to 0 .

As described above, (i) the dynamic response can be simulated in terms of the critical period by an equation of the form of equation (1), (ii) the dynamic response of the problem considered depends on the value of Ts-ave, given by equation (3b), (iii) the response of Figs. 4 illustrate that the dynamic response (a) does not exist for Ts-ave $=0$, (b) as Ts-ave increases, the dynamic effect increases and it produces maximum response approximately when Ts-ave $=\mathrm{Tm}$ and (c) as Ts-ave further increases beyond $\mathrm{Tm}$, it decreases the final seismic displacement along the slip surface $\left(u_{f}\right)$ towards zero and (iv) the dynamic effect is affected by the magnitude of the sliding seismic displacement. Thus, we apply equation (1) by assuming that $\mathrm{Ta}=\mathrm{Tb}$ and replacing and Ts with Ts-ave and we obtain

$$
\begin{array}{ll}
T s-a v e \leq T a & \text { Kdyn(Ts-ave })=1+\text { A Ts-ave } / \text { Ta } \\
T s-a v e>T a & \text { Kdyn }(\text { Ts-ave })=1+(1+\mathrm{A})(\text { Ta } / \text { T-ave })^{\mathrm{B}}
\end{array}
$$

where Ta is the Ts-ave value where Kdyn is maximum and the parameters A, B determine the peak value and the post-peak rate of decrease of the dynamic effect, as illustrated in Fig. 6 . Section 2.4 above, described that the dynamic effect diminishes as the seismic displacement increases, or, equivalently, as the critical acceleration value for relative motion increases. Indeed, at the time intervals where seismic displacement accumulates, the body above the slip surface is separated from and moves independently from the body below the slip surface, and thus the relationship between the dynamic effect and the factor Ts-ave ceases to exist. 
We define as (Rt) the ratio of the sum of times where the seismic displacement accumulates (ts) by the total duration time of the applied seismic motion:

$$
\mathrm{Rt}=\mathrm{ts} / \mathrm{tt}
$$

Based on the discussion above, it is inferred that as (Rt) increases towards 1 , the dynamic effect diminishes. Thus, as Rt increases, the factors A and B of equation (5b) decrease, and in particular for large values of Rt, A and B tend to zero.

Yet, the factors $\mathrm{tt}$, ts are not usually used or specified on earthquake engineering. On the other hand, the intensity of a seismic motion is best defined by the Arias Intensity measure (Ia) $[5,6]$ and the corresponding magnitude of the relative slip which occurs can be identified by $\mathrm{u}_{\mathrm{f}}$ bl. Thus, we approximate the factor Rt of equation (6a) with the factor R't defined by commonly used and well defined parameters Ia and $\mathrm{u}_{\mathrm{f}-\mathrm{bl}}$ as

$$
\mathrm{R}^{\prime} \mathrm{t}=\left(\mathrm{u}_{\mathrm{f}-\mathrm{b} / \mathrm{Ia})}\right.
$$

As R't increases, the factors $\mathrm{A}$ and $\mathrm{B}$ of equation (5b) decrease towards zero and thus we can write

$$
\begin{aligned}
& \mathrm{A}=\mathrm{a} 1\left(\mathrm{Ia} / \mathrm{u}_{\mathrm{f}-\mathrm{bl}}\right)^{\mathrm{a} 2} \\
& \mathrm{~B}=\mathrm{b} 1\left(\mathrm{Ia} / \mathrm{u}_{\mathrm{f}-\mathrm{bl}}\right)^{\mathrm{b} 2}
\end{aligned}
$$

where a1, a2, b1, b2 are model parameters.

It can be noted that equations ( $5 \mathrm{~b})$ and ( $5 \mathrm{~d})$ predict that, similarly to the response described in section 2.4, (a) A and B decrease, and the dynamic response decreases, as Ar decreases and $\mathrm{u}_{\mathrm{f}}$ increases and (b) A and B tend to zero and the dynamic response diminishes as Ar tends to zero and as $\mathrm{u}_{\mathrm{f}}$ becomes very large.

(a)

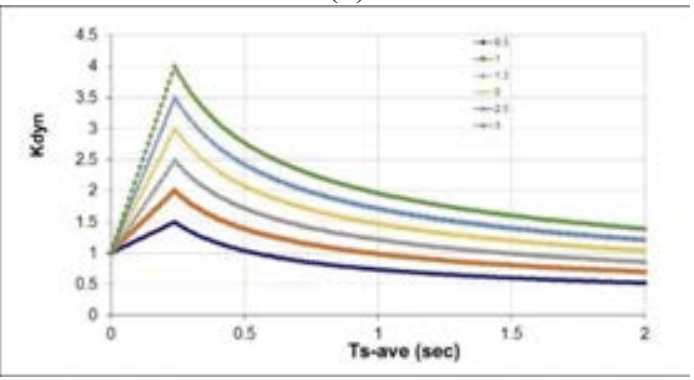

(b)

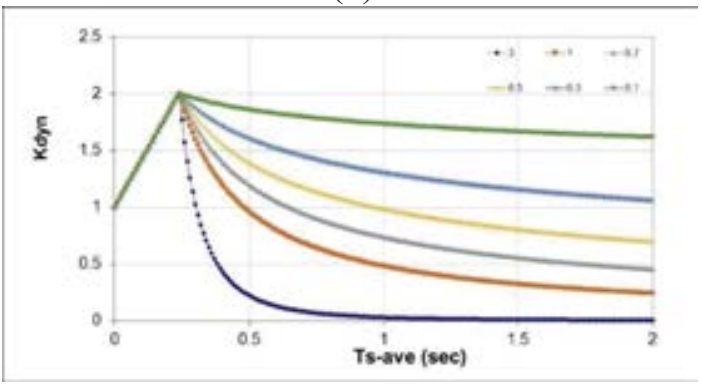

Figure 6: The function Kdyn in terms of (a) A and (b) B. In (a) B=0.5 and in (b) A=1. 


\section{DATA BASE AND PARAMETRIC ANALYSES}

A data base of seismic motions was obtained using the ESM site (the Engineering StrongMotion Database), which contains waveforms with magnitude $\geq 4.0$, mainly recorded in the European-Mediterranean regions and the Middle-East and provides a set of facilities to search, select, download and analyze ground-motion data. It is obtained by selecting the Northern and Eastern components of seismic motions with the following restrictions: Soil type according to EC8 : A (Rock), $\max (\mathrm{PGA})>100 \mathrm{~cm}^{2} / \mathrm{s}, \quad \mathrm{M}>5$. The reason of the selection described above is that (a) the Katsenis et al. $[9,11]$ model input motions must correspond to seismic motions at rock sites without the amplification and modification phenomena that seismic motions exhibit as they pass thru soil layers and (b) seismic motions with $\max (\mathrm{PGA})<100 \mathrm{~cm}^{2} / \mathrm{s}$ and $\mathrm{M}<5$ typically do not cause intolerable seismic displacement along slip surfaces.

The data base included 56 cases, sorted in descending PGA order, given in Appendix A. For the present application four seismic motions were selected. In particular, as the seismic displacement greatly depends on PGA, the seismic motions were selected staring from the first and taking the next after passing 12. In this way, the seismic motions No1, 13, 25, 37 were selected, having a variety of PGA values, ranging from large to small PGA. Table 1 gives the main characteristics of these applied seismic motions.

Coupled linear dynamic parametric analyses were performed using the Katsenis et al. [9, 11] model, and more specifically the corresponding numerical code DIAS [11]. All the seismic motions described above were applied at the base of soil column with $\mathrm{h}_{1}=\mathrm{h}_{2}=15 \mathrm{~m}$. The shear wave velocities of the two bodies considered are given in table 2. In each seismic motion, at the slip surface three $a_{c}$ values were assumed, selected in such a way that $u_{f-b l}$ equals $0.01,0.1,1 \mathrm{~m}$, which cover the range of typical values of typical field problems of instability interest. In addition , $\lambda_{1}=\lambda_{2}=0.05, \rho_{1}=\rho_{2}=2 \mathrm{t} / \mathrm{m}^{3}$ were assumed.

\begin{tabular}{|c|c|c|c|c|c|l|c|}
\hline No & Region & Date & ML & $\begin{array}{c}\text { Epicentral } \\
\text { Distance }\end{array}$ & $\begin{array}{c}\text { PGA } \\
\left(\mathrm{cm} / \mathrm{s}^{2}\right)\end{array}$ & Ia $(\mathrm{cm} / \mathrm{s})$ & Tcr (s) \\
\hline 1 & Turkey, Düzce & $11 / 12 / 1999$ & 6.6 & 27.4 & -1010 & 1331.53 & 0.25 \\
\hline 2 & Montenegro & $15 / 04 / 1979$ & 6.8 & 62.9 & 211 & 73.32 & 0.25 \\
\hline 3 & Turkey, Düzce & $12 / 11 / 1999$ & 6.6 & 30.3 & -157 & 44.30 & 0.25 \\
\hline 4 & Italy, Umbria & $30 / 10 / 2016$ & 6.1 & 46.6 & 121 & 19.68 & 0.13 \\
\hline
\end{tabular}

Table 1: The main characteristics of the applied seismic motions.

\begin{tabular}{|l|r|r|r|r|r|r|r|r|r|r|r|}
\hline $\mathrm{V}_{\mathrm{s}-1}(\mathrm{~m} / \mathrm{s})$ & 50 & 100 & 130 & 180 & 270 & 370 & 470 & 580 & 700 & 1000 & 2000 \\
\hline $\mathrm{V}_{\mathrm{s}-2}(\mathrm{~m} / \mathrm{s})$ & 75 & 1500 & 300 & 500 & 750 & 5000 & & & & & \\
\hline
\end{tabular}

Table 2: Shear wave velocities applied in the parametric analyses

\section{EVALUATION OF MODEL PARAMETERS}

Fig. 7 gives the obtained results of the parametric analyses: The ratio $u_{f} / u_{f-b l}$ in terms of Ts-ave in terms of applied seismic motion and $\mathrm{u}_{\mathrm{f}-\mathrm{bl}}$ is given for all seismic motions. Similarly to the theory described above, it can be observed that plotting the results for each case of seismic motion and $\mathrm{u}_{\mathrm{f}-\mathrm{bl}}$ values in terms of Tave has small scatter and this is true especially for small 
$\mathrm{u}_{\mathrm{f}-\mathrm{bl}}$ values. It is also worth noting that in the results presented in Fig. $7, \mathrm{u}_{\mathrm{f}} / \mathrm{u}_{\mathrm{f}-\mathrm{bl}}$ was plotted in terms of Ts1 instead of Ts-ave also, and it was observed that the scatter was much larger.

(1)
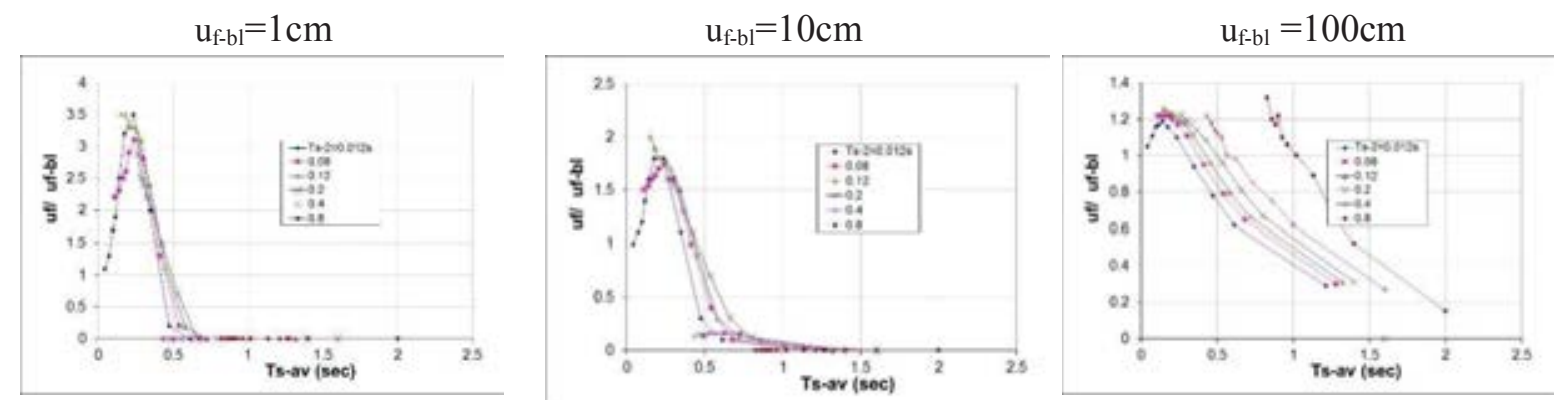

(2)
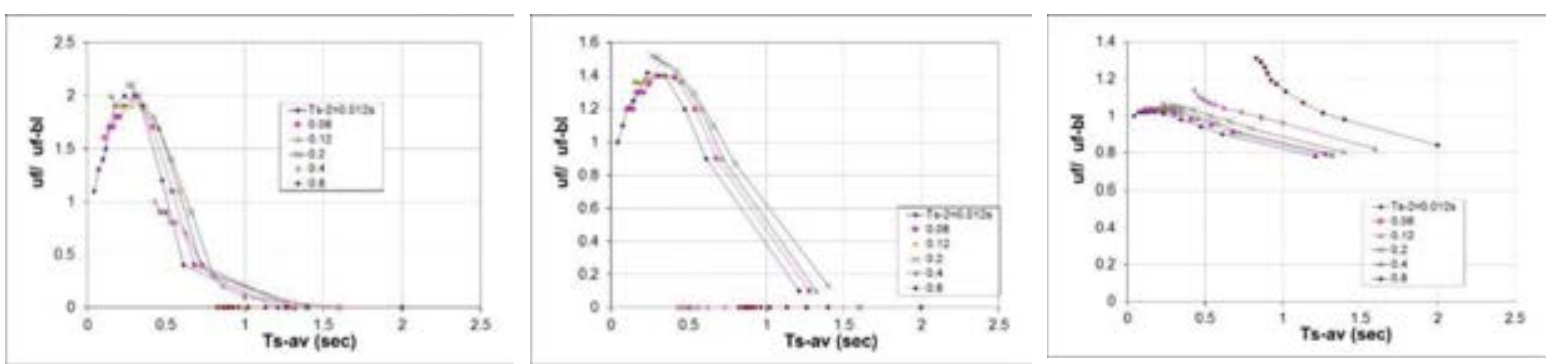

(3)
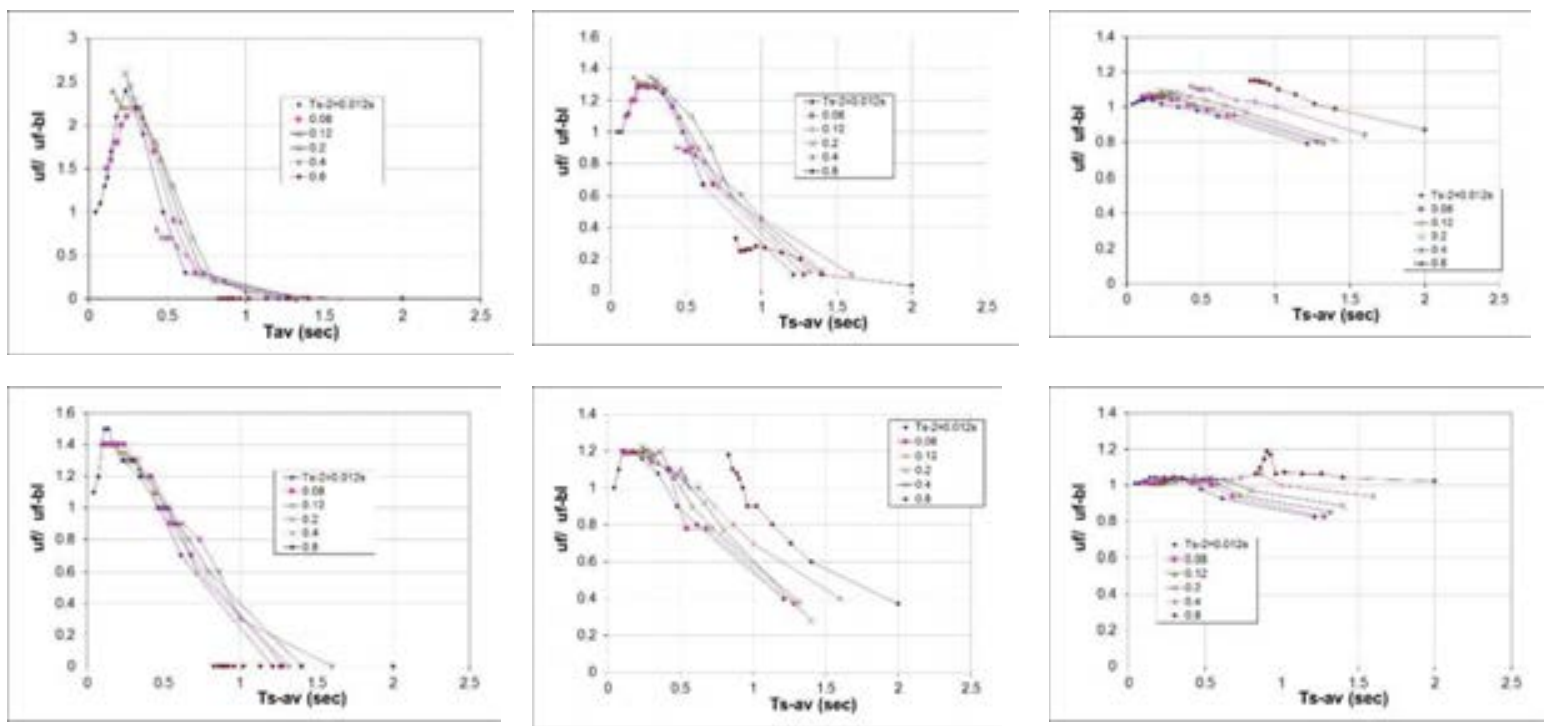

Figure 7: The function Kdyn for the seismic motions (1)-(4) in terms of $\mathrm{u}_{\mathrm{f}-\mathrm{bl}}$.

For each case of seismic motion and $\mathrm{u}_{\mathrm{f}-\mathrm{bl}}$ value, the model parameters simulating the dynamic response according to equation (5) were obtained. In all cases, the seismic response was simulated well when

$$
\mathrm{Ta}=0.3 \mathrm{~s}
$$

It can be noted that this value is consistent with section 2.1 statement that in rock sites Tm does not exceed $0.4 \mathrm{~s}$. With $\mathrm{Ta}=0.3 \mathrm{~s}$, table 3 gives the obtained factors $\mathrm{A}$ and $\mathrm{B}$. Fig. 8 presents the parameters of table 3: The factors A and B in terms of (a) (1/ $\left.\mathrm{u}_{\mathrm{f}-\mathrm{bl}}\right)$, (b) Ia, (c) (Ia/ $\left.\mathrm{u}_{\mathrm{f}-\mathrm{bl}}\right)$ are given. 
Strong correlations are observed in all cases and as illustrated in Fig 8c, the best-fit correlations of the relations ( $5 c)$ and (5d), according to equation ( $5 b)$, occur when,

$$
\begin{aligned}
& \mathrm{a} 1=0.17, \mathrm{a} 2=0.39 \\
& \mathrm{~b} 1=0.20, \mathrm{~b} 2=0.35
\end{aligned}
$$

As illustrated in Fig. 8c, the coefficient of determination is larger than 0.85 in all cases and as the coefficient of determination is close to unity, it is inferred that the proposed equation describes well the computed response

(a) Factor $\mathrm{A}$

\begin{tabular}{|c|c|c|c|c|}
\hline$I a(\mathrm{~cm} / \mathrm{s}):$ & $u_{f-b l}(\mathrm{~cm}): 1331.5$ & 73.3 & 44.3 & 19.7 \\
\hline 1 & 2.5 & 1.2 & 1.2 & 0.5 \\
\hline 10 & 1.2 & 0.4 & 0.3 & 0.2 \\
\hline 100 & 0.2 & 0.2 & 0.1 & 0.1 \\
\hline
\end{tabular}

(b) Factor B

\begin{tabular}{|c|c|c|c|c|}
\hline$I a(\mathrm{~cm} / \mathrm{s}):$ & $u_{f-b l}(\mathrm{~cm}): 1331.5$ & 73.3 & 44.3 & 19.7 \\
\hline 1 & 1.8 & 0.8 & 0.8 & 0.7 \\
\hline 10 & 1 & 0.55 & 0.55 & 0.43 \\
\hline 100 & 0.55 & 0.1 & 0.1 & 0.1 \\
\hline
\end{tabular}

Table 3: The model parameters A and B simulating the dynamic response according to equations (5), for each case of the $\mathrm{u}_{\mathrm{f}-\mathrm{bl}}(\mathrm{cm})$ and $\mathrm{Ia}(\mathrm{cm} / \mathrm{s})$ of the seismic motion 
Factor A

(a)

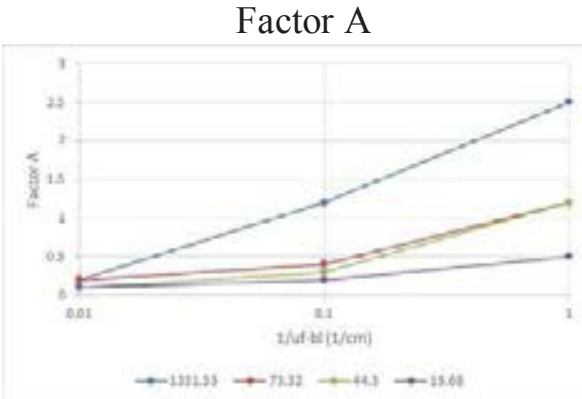

(b)

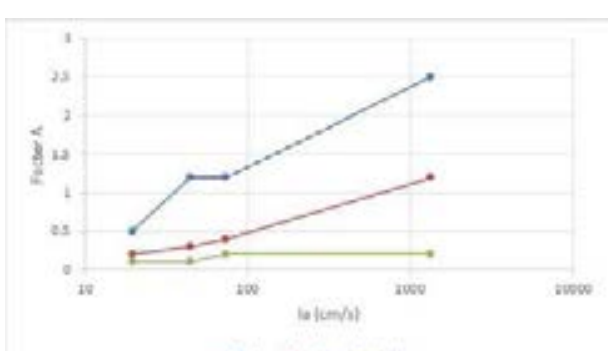

(c)

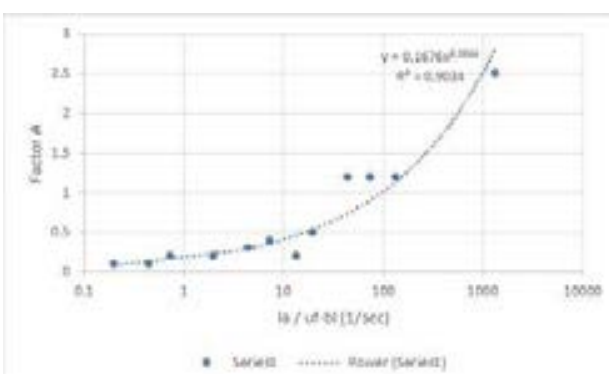

Factor B
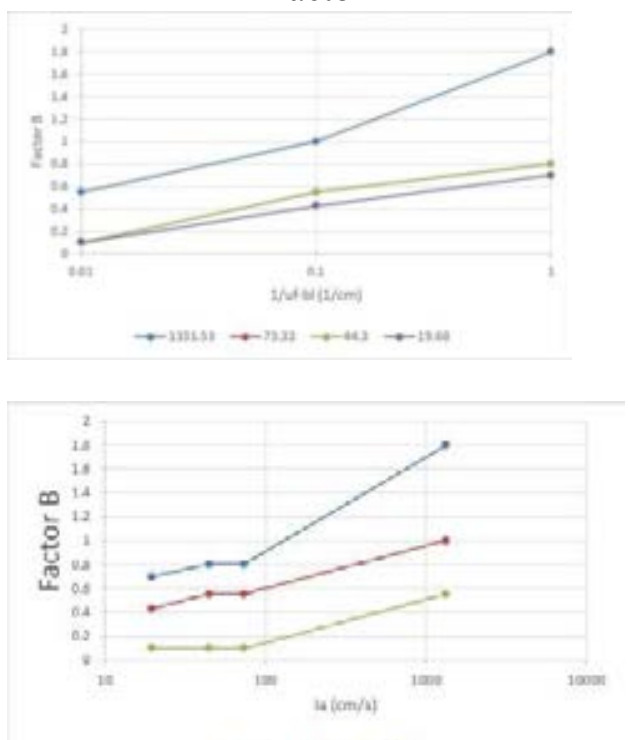

$\rightarrow-1+-1+\infty$ in

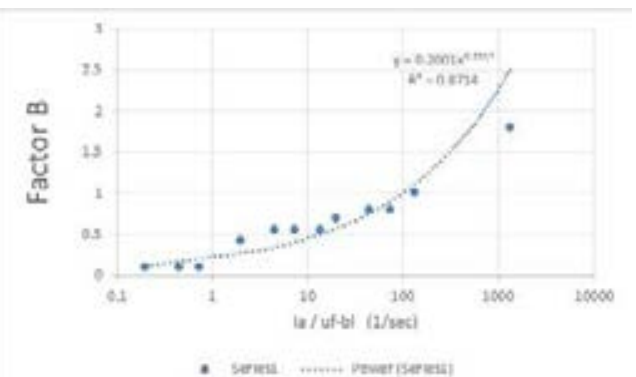

- Sereis ........ veveriseresia

Figure 8: Analysis of the results of the table 3: The factors A and B in terms of (a) $1 / \mathrm{u}_{\mathrm{f}-\mathrm{bl}}$, (b) Ia, (c) Ia/ $\mathrm{u}_{\mathrm{f}-\mathrm{bl}}$.

\section{DISCUSSION}

\subsection{Validation and Application}

Partial validation of the proposed equation (5) is the fact that the coefficient of determination $\left(\mathrm{R}^{2}\right)$ of the fitting parameters $\mathrm{a} 1$, $\mathrm{a} 2$ and $\mathrm{b} 1, \mathrm{~b} 2$ of the proposed equation is near unity and certainly larger than 0.8 . However, it is desirable to perform additional analyses to validate equation (5), especially as only four seismic motions were used to derive it. For this purpose, more parametric analysis to validate the proposed equation and analyze its error may be performed by applying all the seismic motions of table A1, as well as different soil profiles.

Furthermore, because deterministic methods obtaining empirical expressions predicting the seismic displacement of slopes do not rationally take into account the uncertainty of these expressions, researchers have recently turned to the probabilistic approach: (a) Creating probability curves of an annual exceedance of a specific value [15], or (b) fragility curves which give the possibility of exceeding a certain seismic displacement value in the design time depending on the properties of the seismic excitation and of the slope [16]. Thus, it is desirable 
to extend and modify as necessary the proposed equation (5) by applying probabilistic methods.

\subsection{Effect of non-linearity}

Soil behaves linearly only at very small shear strains, well below the typical shear strains exerted in soil profiles near severe earthquakes [11]. It is inferred that for accurate predictions, the linear methods described above must be extended with constitutive equations simulating the non-linear soil response. Under dry conditions the degradation of the shear modulus with shear strain must be simulated. The Katsenis et al [11] model simulates this degradation in terms of the Plasticity Index of the Soil (PI), as proposed by the state-of-the-art model of Vucevic and Dobry [17], shown in Fig. 9a. Typical results of numerical simulations illustrating the profound effect of soil non-linearities on the seismic response are given in Fig. 9b. The case of the Aegion 1995 seismic motion with ac $=0.5 \mathrm{~m} / \mathrm{s} 2, \mathrm{~V}_{\mathrm{s}-2}=\mathrm{V}_{\mathrm{s}-1}, \mathrm{~h}_{1}=\mathrm{h}_{2}=15 \mathrm{~m}$, $\rho_{1}=\rho_{2}=2 \mathrm{Mg} / \mathrm{m} 3, \lambda_{1}=\lambda_{2}=0.15, \mathrm{PI}_{1}=\mathrm{PI}_{2}=0$ is considered.

Katsenis et al. [11] observed that the effect of soil non-linearities can be simulated in linear analyses by reducing the shear wave velocity to the average value one during the non-linear dynamic simulation. Thus, it is inferred that equation (5) may potentially be extended to predict the non-linear soil response by proposing methods which adequately reduce the $\mathrm{V}_{\mathrm{s}-1}$ and $\mathrm{V}_{\mathrm{s}-2}$ values in terms of the intensity of the applied seismic motion and the soil stiffness.

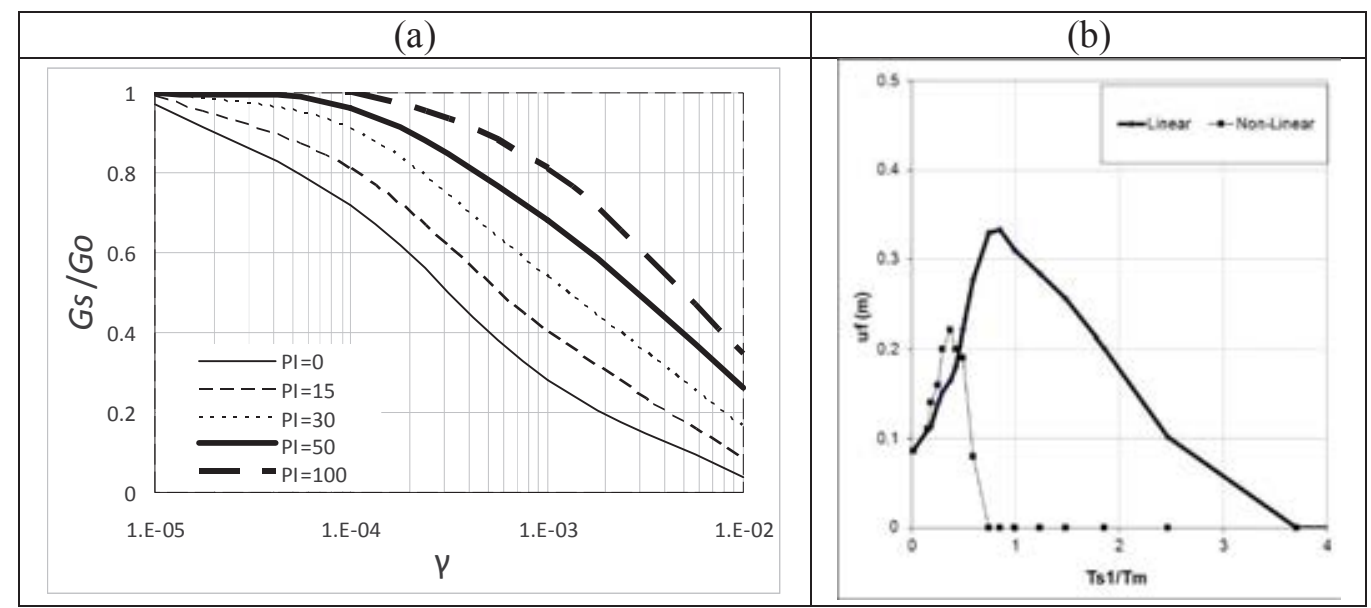

Figure 9: (a) Shear modulus degradation versus shear strain in terms of PI, as proposed by Vucevic and Dobry [17], (b) The computed displacement $\left(\mathrm{u}_{\mathrm{f}}\right)$ by Katsenis et al. [11] for the linear and nonlinear dynamic analyses versus Ts1/Tm for a specific case, described in the text. 


\section{CONCLUSIONS}

- Expressions have been proposed predicting the seismic displacement of slopes in terms of characteristics of the applied seismic motion and the critical horizontal acceleration for sliding and only the dynamic characteristics of the sliding mass [7]. Only Katsenis et al. [9] proposed empirical expressions in terms of the soil profile both above and below the slip surface. Yet, their expressions are in terms of the soil profile type of the slope according to Eurocode 8 and not related to the dominant profile period.

- The present work proposes equation (5) simulating the effect of the dynamic response on the seismic displacement of slopes in terms of the dominant period of the soil profile both above and below the slip surface.

- This equation is based on state-of-the-art descriptions of the dynamic response, results of previous dynamic seismic sliding displacement analyses and numerical predictions of the model of Fig. $3 b$.

- It is desirable to perform more parametric analysis to validate the proposed equation and analyze its error.

- The proposed equation may be extended to predict the non-linear soil response.

\section{REFERENCES}

[1] Katsenis L. C. Nonlinear dynamic sliding movement of slopes, Doctoral Dissertation, Democritus University of Thrace, School of Engineering, Department of Civil Engineering, Xanthi, June, 2020.

[2] Newmark, N. M. Effects of earthquakes on dams and embankments. Geotechnique, 55 (2), 139-159, 1965.

[3] Ambraseys N. and Menu J. Earthquake induced ground displacements, Earthquake engineering and structural dynamics, 16, 7, 985-1006, 1998.

[4] Ambraseys N N, Srbulov M. Attenuation of earthquake-induced displacements. Journal of Earthquake Engineering and Structural Dynamics 23: 467-487, 1994.

[5] Jibson R. W. Regression models for estimating coseismic landslide displacement Engineering Geology 91, 209-218, 2007.

[6] Chousianitis K., Gaudio V., Kalogeras I, Ganas A. Predictive model of Arias intensity and Newmark displacement for regional scale evaluation of earthquake - induced landslide hazard in Greece, Soil Dynamics and Earthquake Engineering, 2014.

[7] Bray J. D. and Travasarou T. (2007). Simplified Procedure for Estimating EarthquakeInduced Deviatoric Slope Displacements, Journal of Geotechnical and Geoenvironmental Engineering, 133 (4), 381-392.

[8] Lin J.-S., and Whitman, R.V. Decoupling Approximation to the evaluation of earthquakeinduced plastic slip in earth dams. Earthquake Engineering and Structural Dynamics, 11: 667-678, 1983. 
[9] Katsenis L.C, Stamatopoulos C.A., Panoskaltsis V.P.,, Thomaidou K. Seismic sliding displacement of slopes in terms of soil profile type Non-linear dynamic seismic slid-ing movement of dry slopes, COMPDYN 2019, 7th International Conference on Computational Methods in Structural Dynamics and Earthquake Engineering, 24-26 June, Crete, Greece, 2019.

[10] European Standard. Eurocode 8: Design of structures for earthquake resistance, Final Draft, prEN 1998-5, December, 2003.

[11] Katsenis L.C., Stamatopoulos C.A., Panoskaltsis V.P. Non-linear dynamic seismic sliding movement of dry slopes, COMPDYN 2019, 7th International Conference on Computational Methods in Structural Dynamics and Earthquake Engineering, 24-26 June, Crete, Greece, 2019.

[12] Katsenis L.C., Stamatopoulos C.A., Panoskaltsis V.P., Di B. Prediction of large seismic sliding movement of slopes using a 2-body non-linear dynamic model with a rotating stick-slip element. Soil Dyn Earthq Eng, 2020.

[13] Rathje E. M. and Bray J. D. An examination of simplified earthquake induced displacement procedures for earth structures. Can. Geotech. J. 36: 72-87, 1999.

[14] Anastasopoulos I. , Gazetas G., Loli M., Apostolou M., Gerolymos N. Soil failure can be used for seismic protection of structures, Bull Earthquake Eng, 8:309-326, 2010.

[15] Rathje E. M., Wang Y., Stafford P. J., Antonakos G. \& Saygili G. Probabilistic assessment of the seismic performance of earth slopes. Bulletin of Earthquake Engineering volume 12, 1071-1090, 2014.

[16] Jafarian Y., Lashgari A. and Miraei M. Multivariate Fragility Functions for Seismic Landslide Hazard Assessment, Journal of Earthquake Engineering, 2018.

Vucetic M. And Dobry R. "Effect of soil plasticity on cyclic response, Journal of the Geotechnical Division, ASCE, 117 (1), 1991. 


\section{Appendix}

Table A1. Seismic motions collected and their magnitude and distance.

\begin{tabular}{|c|c|c|c|c|}
\hline No & Name & Date & $\mathbf{M}(\mathbf{M w})$ & Epic. Distance (km) \\
\hline 1 & Turkey, Düzce & $12 / 11 / 1999$ & 6.6 & 27.4 \\
\hline 2 & Turkey, Düzce & $12 / 11 / 1999$ & 6.6 & 27.2 \\
\hline 3 & Italy, Umbria & $30 / 10 / 2016$ & 6.1 & 12 \\
\hline 4 & Italy, Abruzzo & $07 / 04 / 2009$ & 5.4 & 3.6 \\
\hline 5 & Italy, Umbria & $30 / 10 / 2016$ & 6.1 & 18.6 \\
\hline 6 & Turkey, Kocaeli & 13/09/1999 & 5.8 & 13.8 \\
\hline 7 & Turkey, Düzce & $12 / 11 / 1999$ & 6.6 & 25.9 \\
\hline 8 & Greece, Ioannina & $15 / 10 / 2016$ & 5.6 & 55.9 \\
\hline 9 & Greece, Ioannina & $16 / 10 / 2016$ & 4.8 & 53.3 \\
\hline 10 & Italy, Umbria & $10 / 30 / 2016$ & 6.1 & 10.5 \\
\hline 11 & Turkey, Düzce & $12 / 11 / 1999$ & 6.6 & 32.3 \\
\hline 12 & Montenegro & $15 / 04 / 1979$ & 6.8 & 62.9 \\
\hline 13 & Italy, Lazio & $24 / 08 / 2016$ & 6 & 32.9 \\
\hline 14 & Italy, Marche & $26 / 10 / 2016$ & 5.4 & 11.5 \\
\hline 15 & Turkey, Kocaeli & 17/08/1999 & 7.25 & 3.4 \\
\hline 16 & Italy, Marche & $26 / 10 / 2016$ & 5.4 & 16.7 \\
\hline 17 & Montenegro & $15 / 04 / 1979$ & 6.8 & 19.7 \\
\hline 18 & Italy, Marche & $26 / 10 / 2016$ & 5.4 & 15.2 \\
\hline 19 & Italy, Umbria & $06 / 10 / 1997$ & 5.4 & 20.8 \\
\hline 20 & Italy, Umbria & $09 / 26 / 1997$ & 5.8 & 21.6 \\
\hline 21 & Italy, Calabria & $25 / 10 / 2012$ & 5 & 2.4 \\
\hline 22 & Italy, Umbria & $14 / 10 / 1997$ & 5.5 & 8.7 \\
\hline 23 & Italy, Calabria & $09 / 09 / 1998$ & 5.5 & 18 \\
\hline 24 & Italy, Abruzzo & $18 / 01 / 2017$ & 5.4 & 19.2 \\
\hline 25 & Turkey, Düzce & 12/11/1999 & 6.6 & 30.3 \\
\hline 26 & Italy, Umbria & $26 / 09 / 1997$ & 5.6 & 24.2 \\
\hline 27 & Turkey, Düzce & 12/11/1999 & 6.6 & 27.4 \\
\hline 28 & Bosnia and Herzegovina & 1990-04-03 & 4.8 & 22 \\
\hline 29 & Italy, Abruzzo & $18 / 01 / 2017$ & 5.1 & 37.9 \\
\hline 30 & Italy, Abruzzo & $07 / 04 / 2009$ & 5.4 & 15.6 \\
\hline 31 & Italy, Umbria & $30 / 10 / 2016$ & 6.1 & 26 \\
\hline 32 & Italy, Campania & $29 / 12 / 2013$ & 5 & 8.5 \\
\hline 33 & Turkey, Düzce & 12/11/1999 & 6.6 & 34.7 \\
\hline 34 & Greece, Ioannina & $16 / 10 / 2016$ & 4.5 & 62.4 \\
\hline 35 & Italy, Marche & $26 / 10 / 2016$ & 5.9 & 31.6 \\
\hline 36 & Italy, Calabria & $25 / 10 / 2012$ & 5 & 10.7 \\
\hline 37 & Italy, Umbria & $30 / 10 / 2016$ & 6.1 & 46.6 \\
\hline 38 & Croatia, zupanija & $27 / 11 / 1990$ & 5.6 & 56.9 \\
\hline 39 & Greece, Athens & $07 / 09 / 1999$ & 5.8 & 19.7 \\
\hline 40 & Italy, Marche & $26 / 10 / 2016$ & 5.4 & 22.8 \\
\hline 41 & Italy, Marche & $26 / 10 / 2016$ & 5.9 & 17.4 \\
\hline 42 & Greece, Peloponeze & 13/10/1997 & 5.8 & 51.4 \\
\hline 43 & Italy, Abruzzo & 18/01/2017 & 5.4 & 31.4 \\
\hline 44 & Italy, Calabria & $25 / 10 / 2012$ & 5 & 9.4 \\
\hline 45 & Greece, Rodos & 24/01/2019 & 5.2 & 86.3 \\
\hline 46 & Italy, Umbria & $07 / 05 / 1984$ & 5.9 & 10.1 \\
\hline 47 & Italy, Abruzzo & $18 / 01 / 2017$ & 5.4 & 20.7 \\
\hline 48 & Turkey, Düzce & 12/11/1999 & 6.6 & 15.6 \\
\hline 49 & Italy, Catania & $13 / 12 / 1990$ & 5.6 & 36.9 \\
\hline 50 & Italy, Abruzzo & $18 / 01 / 2017$ & 5.3 & 34.5 \\
\hline 51 & Italy, Marche & $26 / 10 / 2016$ & 5.9 & 60.2 \\
\hline 52 & Italy, Abruzzo & $18 / 01 / 2017$ & 5.4 & 17 \\
\hline
\end{tabular}


Table A2. Characteristics of the seismic motions of table A1.

\begin{tabular}{|c|c|c|c|c|c|c|}
\hline & \multicolumn{2}{|c|}{ PGA $\left(\mathrm{cm} / \mathrm{s}^{2}\right)$} & \multicolumn{2}{|c|}{ Ia $(\mathrm{cm} / \mathrm{s})$} & \multicolumn{2}{|c|}{ Tcr (s) } \\
\hline No & $E$ & $\mathrm{~N}$ & $\mathrm{E}$ & $\mathrm{N}$ & $\mathrm{E}$ & $\mathrm{N}$ \\
\hline 1 & -743 & -1010 & 649.35 & 1331.53 & 0.26 & 0.25 \\
\hline 2 & 489 & -888 & 198.95 & 979.16 & 0.32 & 0.4 \\
\hline 3 & 779 & -850 & 555.65 & 608.67 & 0.17 & 0.15 \\
\hline 4 & 652 & 304 & 89.77 & 49.83 & 0.19 & 0.2 \\
\hline 5 & 426 & 385 & 201.09 & 192.23 & 0.25 & 0.16 \\
\hline 6 & 317 & -74 & 30.49 & 3.76 & 0.23 & 0.22 \\
\hline 7 & 277 & 298 & 156.33 & 185.24 & 0.37 & 0.2 \\
\hline 8 & 287 & 241 & 64.36 & 84.47 & 0.36 & 0.32 \\
\hline 9 & 284 & 194 & 23.12 & 22.85 & 0.3 & 0.34 \\
\hline 10 & 274 & 273 & 80.30 & 70.73 & 0.65 & 0.22 \\
\hline 11 & -254 & 116 & 100.62 & 19.58 & 0.28 & 0.32 \\
\hline 12 & -249 & 211 & 45.88 & 73.32 & 0.29 & 0.25 \\
\hline 13 & 242 & 186 & 30.33 & 12.33 & 0.4 & 0.12 \\
\hline 14 & -194 & 239 & 23.44 & 19.74 & 0.13 & 0.16 \\
\hline 15 & 229 & 164 & 97.78 & 73.72 & 0.29 & 0.28 \\
\hline 16 & -218 & -130 & 31.84 & 17.65 & 0.12 & 0.12 \\
\hline 17 & 210 & 173 & 72.89 & 61.59 & 0.7 & 0.17 \\
\hline 18 & 177 & -192 & 9.88 & 8.89 & 0.26 & 0.13 \\
\hline 19 & -101 & -184 & 6.57 & 13.84 & 0.28 & 0.22 \\
\hline 20 & 184 & 164 & 23.49 & 27.93 & 0.32 & 0.19 \\
\hline 21 & 182 & -130 & 10.69 & 8.99 & 0.19 & 0.28 \\
\hline 22 & 94 & -176 & 5.07 & 11.43 & 0.24 & 0.24 \\
\hline 23 & -152 & -162 & 10.26 & 15.68 & 0.11 & 0.5 \\
\hline 24 & 82 & -161 & 3.45 & 9.71 & 0.13 & 0.28 \\
\hline 25 & 121 & -157 & 41.07 & 44.30 & 0.36 & 0.25 \\
\hline 26 & 111 & 152 & 5.79 & 11.30 & 0.25 & 0.22 \\
\hline 27 & -133 & -148 & 27.54 & 37.35 & 0.19 & 0.24 \\
\hline 28 & 109 & -139 & 8.00 & 12.37 & 0.05 & 0.08 \\
\hline 29 & -83 & -138 & 2.47 & 4.92 & 0.06 & 0.1 \\
\hline 30 & 88 & 131 & 2.47 & 4.58 & 0.1 & 0.32 \\
\hline 31 & -131 & 114 & 16.15 & 11.65 & 0.2 & 0.22 \\
\hline 32 & 130 & -77 & 9.45 & 8.56 & 0.12 & 0.1 \\
\hline 33 & -129 & 98 & 24.36 & 22.52 & 0.32 & 0.32 \\
\hline 34 & 127 & -114 & 6.37 & 9.41 & 0.2 & 0.3 \\
\hline 35 & -117 & -125 & 7.22 & 9.25 & 0.08 & 0.13 \\
\hline 36 & -117 & -124 & 5.38 & 5.63 & 0.12 & 0.19 \\
\hline 37 & -90 & 121 & 9.33 & 19.68 & 0.09 & 0.13 \\
\hline 38 & -121 & 121 & 19.87 & 18.62 & 0.35 & 0.16 \\
\hline 39 & -119 & -108 & 9.48 & 6.54 & 0.1 & 0.25 \\
\hline 40 & -119 & 100 & 5.88 & 5.80 & 0.2 & 0.2 \\
\hline 41 & -119 & -84 & 8.59 & 8.63 & 0.16 & 0.2 \\
\hline 42 & -116 & 117 & 28.17 & 19.12 & 0.3 & 0.22 \\
\hline 43 & 109 & -116 & 7.90 & 10.43 & 0.1 & 0.1 \\
\hline 44 & 96 & -114 & 3.20 & 3.45 & 0.09 & 0.1 \\
\hline 45 & 43 & 112 & 3.34 & 11.19 & 0.35 & 0.4 \\
\hline 46 & 110 & 98 & 5.29 & 6.23 & 0.25 & 0.11 \\
\hline 47 & 95 & 108 & 5.97 & 8.78 & 0.12 & 0.29 \\
\hline 48 & 106 & 74 & 11.02 & 6.42 & 0.1 & 0.26 \\
\hline 49 & 105 & 61 & 5.53 & 4.71 & 0.08 & 0.22 \\
\hline 50 & -68 & 103 & 3.83 & 6.41 & 0.1 & 0.1 \\
\hline 51 & 71 & 103 & 4.49 & 4.29 & 0.19 & 0.1 \\
\hline 52 & -76 & -102 & 3.46 & 5.78 & 0.17 & 0.17 \\
\hline
\end{tabular}

